\title{
Optimization Models of Food Processing Wild- Growing Products with Expert Assessments
}

\author{
Yaroslav M. Ivanyo \\ Irkutsk State Agricultural University named after A.A. Ezhevsky \\ Irkutsk, Russia \\ pnr@igsha.ru
}

\begin{abstract}
The paper proposes models for maximizing cluster incomes for the harvesting of wild-growing products, taking into account the areas and possible fishing volumes, yields of taiga resources, labor costs and production costs. A multi-criteria linear programming problem and problems with interval and random parameters are considered. The analysis of the initial data used to model cluster activity is given. The labor costs for obtaining forest products, the yield of wildgrowing plants and the cost of production are proposed to determine by expert means in the form of average and interval estimates. The results of optimization of the procurement of food wild-growing products for potential clusters of the Irkutsk region were obtained.
\end{abstract}

Keywords - mathematical modeling, wild-growing food resources, expert assessments, clusters.

\section{INTRODUCTION}

Forest land covers $89.5 \%$ of the Irkutsk region. According to forestry data and own research [1-5], the region has reserves of wild-growing food resources in the amount of $28 \pm 5.6$ billion rubles. At present, income from the harvesting and processing of wild-growing food products ranges from 100 to 250 million rubles. It determines a significant potential for the use of taiga wealth. Given the fact that high-quality wild-growing food resources are highly valued on the world market $[6,7]$ and contribute to human health, the Irkutsk region is an attractive subject for the export of such taiga products.

Controlling the harvesting of wild-growing food products to increase food production and improve quality is associated with the application of applied extreme problems in the face of uncertainty $[4,8,9$, etc. $]$. In the literature there are a small number of works devoted to models of optimization of wildgrowing products [5, 10-12] caused by information support, the uncertainty of many parameters and the specifics of the problem. Meanwhile, many authors consider the growth characteristics of wild-growing food resources, the possibility of forecasting and estimating stocks, as well as the labor costs for harvesting various types of products $[5,11$, $13-15$, etc.].

The purpose of this work is to build models for optimizing the harvesting of wild-growing food products in the region with uncertain parameters and expert assessments. To achieve this goal, the following tasks were formulated:

- expanding the possibilities of using optimization models for the procurement of wild-growing food products with interval and probabilistic parameters;

\author{
Sofia A. Petrova \\ Irkutsk State Agricultural University named after A.A. Ezhevsky \\ Irkutsk, Russia \\ sofia.registration@mail.ru
}

- the use of expert assessments for solving applied extreme problems of optimizing the harvesting of wild-growing food products.

The practical significance of the work is to determine the possibilities of certain territories for the harvesting, processing and sale of wild plants to create additional jobs, expand the functions of producers and increase the production of environmentally friendly wild-growing products. We should not forget that the region is one of the leading in Russia in timber harvesting; therefore a program for the integrated use of forest resources is needed. It is obvious that the development of the fishery food wildgrowing industry will contribute to the growth of financial revenues to the regional budget and export prospects.

\section{OPTIMIZATION MODELS FOR HARVESTING WILD-GROWING FOOD PRODUCTS FOR CLUSTERS}

Food products wildlife producers and processors can be clustered to improve their performance. In this case, the linear programming problem with interval parameters given in [10] can be written in the following form. With the help of the objective function, the income from harvesting wild plants is maximized:

$$
f=\sum_{k \in K} \sum_{j \in J} \widetilde{c}_{k j} x_{k j} \rightarrow \max
$$

where $\underline{\tilde{c}}_{k j}$ and $\overline{\tilde{c}}_{k j}$ are lower and upper estimates $\tilde{c}_{k j}$ characterizing the minimum and maximum costs of a kilogram of berries, mushrooms, nuts and medicinal plants of a $j$-type for a cluster participant $k$.

The first group of restrictions is related to the yield of berry-bearing plants, nut, medicinal plants and mushrooms, $\mathrm{kg} / \mathrm{ha}$ :

$$
\sum_{k \in K} \sum_{j \in J} \frac{x_{k j}}{\tilde{y}_{k j}} \leq \tilde{S}
$$

where $\underline{y}_{k j}$ and $\overline{\tilde{y}}_{k j}$ are the lower and upper estimates $\tilde{y}_{k j}$ characterizing the minimum and maximum yields of berriesbearing plants, nut, mushrooms and medicinal plants of the $j$ type for the cluster member $k ; \tilde{S}$ - potential area for gathering wild-growing $j$-type products by all cluster members within $\underline{\widetilde{S}} \leq \widetilde{S} \leq \overline{\widetilde{S}} ; ; \underline{\widetilde{S}}$ and $\overline{\widetilde{S}}$ are the lower and upper estimates characterizing the minimum and maximum 
collection areas of the wild-growing $j$-type by all cluster members.

The second group of restrictions is related to the labor costs for harvesting of wild-growing products:

$$
\sum_{k \in K} \sum \tilde{b}_{k j} x_{k j} \leq \tilde{B}
$$

where $\tilde{b}_{k j}$ and $\tilde{\tilde{b}}_{k j}$ are lower and upper estimates $\tilde{b}_{k j}$ characterizing the minimum and maximum number of mandays for harvesting a unit of wild-growing $j$-type products by cluster member $k ; \underline{\boldsymbol{B}}_{k j}$ and $\overline{\widetilde{B}}_{k j}$ - lower and upper estimates characterizing the minimum and maximum number of available man-days for harvesting wild-growing j-type products by the cluster member $k$. Labor resources for harvesting $j$-type of wild-growing plants depend on fruitful areas, laboriousness of picking berries, mushrooms, nut, medicinal plants and employment of the population.

The restriction of the nonnegativity of variables is as follows:

$$
x_{k j} \geq 0 \text {. }
$$

Problem (1)-(4) takes into account the activities of the many participants in the cluster $K$. It is obvious that in this case, in addition to a single-target function, you can use a multi-criteria linear programming problem. When solving multi-criteria problems, various methods are used: convolutions, successive concessions, selection of the main criterion and others [16]. For the particular case of the weighted sum convolution method, the expression (1) can be written as follows

$$
\begin{gathered}
z=\sum_{k \in K} \alpha_{k} f_{k} \rightarrow \max , \\
f_{k}=\sum_{j \in J} \widetilde{c}_{k j} x_{k j},
\end{gathered}
$$

where $f_{k}$ is the objective function of the cluster participant $k$, which characterizes the income, and $\alpha_{k}$ are the weighted coefficients $\alpha_{k} \geq 0$. In this case, $\sum_{k \in K} \alpha_{k}=1$.

Since the coefficients for unknowns in the objective function $\tilde{c}_{j}$ are generally interval estimates, as are the coefficients in the left parts of the constraints $\left(\tilde{y}_{k j}, \tilde{b}_{k j}\right)$ and the right parts $(\tilde{S}, \widetilde{B})$, the simulation result will be a set of optimal values of the objective function depending on their upper and lower estimates and intervals. Of particular interest in solving extreme problems with interval estimates are the upper, lower and median values of the objective function and the corresponding optimal plans.

If you know the empirical or analytical functions of the probability distribution of the yield of wild-growing food resources, the volumes of the products obtained, and other parameters of the extreme problem, then you can use the stochastic programming model to optimize the fishery. For average prices, the linear programming problem with probabilistic values will look like this:

$$
\begin{gathered}
f=\sum_{k \in K} \sum_{j \in J} c_{k j} x_{k j} \rightarrow \max , \\
\sum_{k \in K} \sum_{j \in J} \frac{x_{k j}}{y_{k j}^{p}} \leq S, \\
\sum_{k \in K} \sum_{j \in J} x_{k j} \leq V^{p}, \\
\sum_{k \in K} \sum_{j \in J} b_{k j} x_{k j} \leq B, \\
x_{i j} \geq 0,
\end{gathered}
$$

where $c_{k j}$ is the unit cost of production $j$ for a cluster member $k$, fluctuating in the interval, $x_{k j}$ is the required volume of output $j$ for cluster member $k$; $S$ is the total area of wild-growing resources; $y_{k j}^{p}$ is bio-productivity of wildgrowing resources of the form $j$ for cluster participant $k$, corresponding to probability $p ; V^{p}$ is the total volume of the product produced, associated with the probability $\mathrm{p} ; b_{k j}$ are labor costs for obtaining the unit of production $j$ by the cluster member $k ; B$ is restriction of labor costs.

The complexity of the application of problem (7)-(11) lies in the fact that probabilistic indicators can be described in the presence of a significant amount of data. However, reliable information on the harvesting of wild-growing products takes place only for the period 1961-1991 on cooperative fur farm [13], therefore, the probabilistic description of the indicators of wild-product harvesting is difficult. Another problem is the need for knowledge not of harvesting, and the yield of wild food resources, which further complicates the task of obtaining adequate source data.

To describe the bio-productivity of wild food resources, taking into account these difficulties, the following modeling algorithm is proposed. First, it is assumed that the ranks of the harvesting of wild-growing products are stationary. Secondly, it is proposed that the laws of probability distribution of dimensionless quantities obtained for harvesting wild-growing products (for example, given in [17]) are applicable for assessing the biological productivity of wild-growing plants. Thirdly, the center of probability distribution in the form of an average value is modeled by the method of statistical tests according to experts, who determine the upper and lower values of the parameter. As a result, an approximate probabilistic estimate of the bioproductivity of wild plants can be obtained over a long-term period. A similar algorithm is applicable for other random variables of model (7)-(11).

\section{DATA AND EXPERT ESTIMATES}

Source data are crucial for optimizing the harvesting of wild-growing food resources. The monograph [5] shows the algorithm for their production. 
Since 1992 there has been almost no continuous information on taiga fishing for wild-growing products [13], therefore it is necessary to use sources of literature: monographs and articles, forest regulations for municipalities, electronic resources of regional ministries, legislative documents and others. In addition, different methods are applicable for assessing the current resources of wild berries, pine nut, medicinal and food plants, as well as forecasting parameters with regard to the biological characteristics of resources for one year. At the same time, the short-term prediction of berries and pine nuts is relatively accurate.

Different methods for predicting possible harvesting of wild-growing resources for a long-term perspective based on the statistical properties of wild grass series (the presence of trends, autocorrelation links, cycles, cross-autocorrelation, and others) are considered.

Analysis of the information features of the bioproductivity data of berries, mushrooms, nut, medicinal plants shows that the parameter yield of wild-growing food crops has a high degree of uncertainty, so it can be described using interval or probabilistic estimates.

In many cases, expert opinion can be used as interval estimates. This concerns the yield of berries, mushrooms, pine nut, medicinal plants. To expert estimates can be attributed labor costs in the collection of wild-growing food products. In addition, you can use the opinion of experts on the cost of wild plants.

Analysis of materials on wild-growing products procurement shows that the best expert estimates are those that are specified in the form of upper and lower values of the indicator under consideration. In this case, both individual and collective assessments are used.

With individual expert evaluation for a particular parameter, one upper and one lower value is determined. Collective assessments require the processing of opinions. From the set of upper and lower estimates, you can choose the largest and smallest values. The second way to determine the upper and lower estimates is to average them depending on the number of experts. Let us apply another way, when out of the total number of estimates, the extremal values are the largest and smallest of the many. In this case, secondranking estimates can be used as upper and lower values.

In addition to quantitative estimates of resources, a questionnaire method was used to determine the biological productivity of wild plants on a scale with six gradations: very low, low, medium low, medium high, high and very high. Since the territory of the Irkutsk Region has significant forest cover, foresters and the local population have reliable information about the volumes of wild-growing food resources in a certain area. To determine promising areas for the harvesting of wild-growing food resources, a survey are proposed according to the information card. The map contains the following information:

- name of the item;

- location;

- area of activity;
- remoteness from the settlement;

- the path of the entrance;

- business indicators;

- collection amount;

- availability of buildings, equipment and construction plan (repair).

Processing of questionnaires is carried out by determining the average and interval estimates. Gradations are used based on the testimony of researchers about the interval values of wild-growing food resources, which allows you to convert qualitative data into quantitative.

In the study of the fluctuations of the series on the harvesting of wild-growing food products according to the data of 1961-1991 some features of their relationships are revealed. Despite the fact that there is no synchronicity in the fluctuations of the harvesting of mushrooms, berries, and pine nut, there are weak significant connections with a shift in the harvesting of some species of wild plants relative to others. Four years later, after a high harvest of berries, there is a decrease in the volume of mushroom harvesting. With a shift of 1-2 years, the volume of harvesting berries decreases, and after three years the yield of mushrooms relative to nuts decreases.

Based on the peculiarities of the perennial rows of the procurement of wild-growing food products, we can conclude that their number does not undergo significant changes. At the same time, there is a tendency to asynchronous harvesting of large volumes of berries, pine nut and mushrooms. In other words, in some years, the harvesting of one species of wild-growing culture has been successfully carried out, and in others of other wild plants [5].

If we use the multi-criteria linear programming problem with interval parameters to optimize the harvesting of wild food products, then in the case of using expressions (5) and (6) it is necessary to evaluate the weighted coefficients $\alpha_{k}$. To obtain them, you can use individual or collective expert opinions. When processing expert estimates, the three methods are applicable, described in the case of determining the yield of wild-growing resources, labor costs in the harvest of wild plants and prices for products.

\section{ALGORITHMS FOR SOLVING PROBLEMS TO OPTIMIZE THE HARVESTING OF WILD PLANTS}

The algorithm for solving a linear programming problem with interval parameters for obtaining optimal solutions consists of the following operations:

- preparation of initial data;

- construction of the objective function and constraints;

- modeling by statistical testing of estimates within specified intervals: yield, labor costs, cost of various wild-growing products;

- multiple solution of the linear programming problem; 
- the choice of the upper, lower and median values of the objective function and the corresponding plans from the set of obtained optimal solutions.

In this algorithm, the stage of preparing initial data that can be obtained by various methods (literature, field materials, expert estimates, questionnaires, and prognostic values) is of great importance. The simulation results are associated with fluctuations in interval indices and their combination. The possibility of applying the proposed algorithm is caused by the independence of the yield of various food wild crops.

On the basis of a different number of solutions to the linear programming problem with interval parameters, which were taken from 100 to 1000 , it is shown that 300 iterations are sufficient to estimate the objective function and optimal plans.

The algorithm for solving a linear programming problem with random parameters to determine the optimal solutions consists of the following operations:

- preparation of initial information;

- determination of the laws of probability distribution for random parameters;

- construction of the objective function and constraints;

- modeling by statistical tests of random values of the yield of wild plants according to specified distribution laws;

- multiple linear programming problem solving;

- building the distribution of the dependence of the values of the objective function on the probabilities of the yield of food wild-growing crops;

- determining the values of the objective function and the corresponding plans with given probabilities, for example, $0.05,0.50$ and 0.95 .

In the above algorithm, probabilistic parameters are the yield of wild-growing food crops. Labor resources and the cost of the products obtained are taken as constant values. The accuracy of the simulation results is associated with the correct choice of the laws of probability distribution and the adequacy of the statistical parameters characterizing the variability of the biological productivity of wild plants. It is obvious that in the above algorithm it is possible to provide for fluctuations in labor costs and product costs. Meanwhile, these parameters are interval estimates. In this case, the linear programming problem with random parameters goes into the category of problems with random and interval parameters. This makes it difficult to interpret the results. At the same time, the implementation of such an algorithm is closer to reflecting the real situation than under the condition of averaging labor resources and the cost of production.

As for the multi-criteria task, the algorithm for solving it is additionally connected with obtaining the values of weighted coefficients:
- preparation of initial data;

- determination of weighted coefficients for each cluster member;

- construction of the objective function and constraints;

- modeling by statistical testing of estimates within specified intervals: yield, labor costs, cost of various wild-growing products;

- multiple solution of the linear programming problem;

- the choice of the upper, lower and median values of the objective function and the corresponding plans from the set of obtained optimal solutions.

In fact, the above algorithm is slightly different from the first. To implement it, a strict agreement of the cluster members regarding the estimates of weighted coefficients is necessary and an understanding that participation in the cluster will benefit the harvesters and processors of wildgrowing food products.

\section{IMPLEMENTING MODELS OF HARVEST WILD-GROWING PRODUCTS WITH INTERVAL ESTIMATES}

From the linear programming problems given in this paper, problem (1)-(4) was solved by the example of real objects. Using the model with interval parameters, the harvesting of wild-growing food products for three potential clusters allocated in the territory of the Irkutsk Region has been optimized. Cluster centers are wild plants processing enterprises. Table shows some results of solving the problem (1)-(4). Here are the upper, lower and median values of income according to the planned collection and processing indicators for 2020. The planned volumes of procurement are based on the technical and technological capabilities of enterprises - cluster members. Bio-productivity of wildgrowing food resources, cost indicators of production and reduced labor costs are determined using expert estimates.

When solving the problem (table 1), the possible volumes of harvesting and processing of pine nut, various types of berries and mushrooms, bracken ferns, ramson and medicinal plants are determined. The following conditions are used: restrictions on the areas of procurement and labor resources, costs of material and technical support, and volumes of procurement and processing of products.

As for the volumes of changes in the planned indicators (table) compared with the actual data, in the Irkutsk cluster it is expected to increase the harvesting and processing of wildgrowing products by 6-7 times. For the Zalarinsky cluster, this figure is a value greater than 3-4, and for Ulkansky cluster it corresponds to 10-12, depending on the worst or best scenario of events (minimum and maximum ratings) At the same time, according to median estimates in these three clusters, by 2020, harvesting and processing of wild-growing products will reach more than 422 million rubles. 
TABLE I. UPPER, LOWER AND MEDIAN INCOME ESTIMATES IN ACCORDANCE WITH THE PLANNED (UP TO 2020) INDICATORS OF COLLECTION AND PROCESSING AT ENTERPRISES COMBINED INTO CLUSTERS OF THE IRKUTSK REGION

\begin{tabular}{|c|c|c|c|c|c|c|c|}
\hline \multirow{3}{*}{ Estimates } & \multicolumn{6}{|c|}{ Plan, $t$} & \multirow{3}{*}{$\begin{array}{l}\text { The value of the objective } \\
\text { function, mln. Rub. }\end{array}$} \\
\hline & PIne nut & Berries & Mushrooms & Bracken fern & Ramson & Medicinal herbal plants & \\
\hline & $x_{1}$ & $x_{2}$ & $x_{3}$ & $x_{4}$ & $x_{5}$ & $x_{6}$ & \\
\hline \multicolumn{8}{|c|}{ Irkutsk cluster } \\
\hline Lower & 211 & 203 & 91 & 67 & 34 & 171 & 211,42 \\
\hline Upper & 329 & 283 & 59 & 112 & 38 & 253 & 434,50 \\
\hline Median & 240 & 307 & 72 & 90 & 44 & 179 & 307,69 \\
\hline \multicolumn{8}{|c|}{ Zalarinsky cluster } \\
\hline Lower & 218 & 101 & 53 & 44 & 19 & 119 & 151,45 \\
\hline Upper & 278 & 106 & 94 & 56 & 24 & 202 & 351,68 \\
\hline Median & 325 & 101 & 78 & 39 & 27 & 133 & 237,25 \\
\hline \multicolumn{8}{|c|}{ Ulkansky cluster } \\
\hline Lower & 70 & 32 & 101 & 4 & 19 & 16 & 60,54 \\
\hline Upper & 120 & 31 & 145 & 4 & 12 & 13,058 & 99,15 \\
\hline Median & 89 & 27 & 123 & 4 & 18 & 18 & 78,52 \\
\hline
\end{tabular}

\section{CONCLUSION}

The task of modeling the harvesting of wild-growing food resources is relevant for the Irkutsk Region, since its territory is concentrated in significant operational stocks of berries, mushrooms, pine nut, medicinal and other plant species.

For efficient operation of the suppliers and processors of wild plants, clusters can be organized according to the criteria of the smallest distances between the participants, the specialization of the procurement and the unification of their activities with the processing enterprise.

The paper presents three models for optimizing the procurement of wild-growing food products in relation to clusters. Problems of linear programming with interval and random parameters are formulated, as well as a multi-criteria problem, in which the objective function is determined using weighted coefficients.

The initial data are of great importance for the optimization of cluster activity. They can be divided into field, expert and literary. It is proposed to use individual or collective expert assessments in the form of interval values for determining the yields of wild-growing food resources, labor costs and product costs.

Algorithms for solving linear programming problems under uncertainty with interval and random parameters, as well as a multi-criteria problem, are presented. To achieve maximum income and optimal plans used the method of statistical tests.

For three potential clusters (Irkutsk, Zalarinsky, and Ulkansky), the tasks of optimizing the volumes of harvesting and processing of wild-growing products were solved. The results showed that in two years these clusters are able to increase production by 3-12 times, while receiving more than 400 million rubles of income. The development of the market for environmentally friendly micronutrients and vitamins of wild-growing products has the prospect of exporting products to China, Korea and other countries.

The above methodology for assessing and optimizing the harvesting and processing of wild-growing food resources can be used to create a decision support system with an appropriate knowledge base [18-20, etc.]

\section{REFERENCES}

[1] Law of the Irkutsk Region on the procedure for harvesting food forest resources and collecting medicinal plants by citizens for their own needs [Zakon Irkutskoy oblasti o poryadke zagotovki pishchevykh lesnykh resursov i sbora lekarstvennykh rasteniy grazhdanami dlya sobstvennykh nuzhd], N 119-oz dated December 10, 2007 (as amended by the Law of the Irkutsk Region dated 03.12.2009 N 89/55oz) (in Russian)

[2] On approval of the forest plan of the Irkutsk region [Ob utverzhdenii lesnogo plana Irkutskoy oblasti] (as amended by decrees of the governor of the Irkutsk region from 26.11.2013 n 445-ug, from 26.03.2015 n 50-ug, from 20.01.2016 n 9-ug) (in Russian)

[3] B.P. Vasilko. Methods of accounting for edible mushrooms in the forests of the USSR [Metody ucheta s"yedobnykh gribov v lesakh SSSR] (Science, L., 1968), 67 p. (in Russian)

[4] Ya. M Ivanyo, S.A. Petrova Optimization models of agricultural production in solving problems of assessing natural and man-made risks. Monograph [Optimizatsionnyye modeli agrarnogo proizvodstva $\mathrm{v}$ reshenii zadach otsenki prirodnykh i tekhnogennykh riskov] (Irkutsk, SAU Publishing House Irkutsk:, 2015), 180 p. (in Russian)

[5] Potential reserves of wild-growing resources of the Irkutsk region. Monograph [Potentsial'nyye zapasy dikorastushchikh resursov Irkutskoy oblasti] / Ya.M. Ivanyo [et al.]; edited by Ya.M. Ivanyo. (Irkutsk SAU Publishing House, Irkutsk, 2017), 156 p. (in Russian)

[6] UNCTAD / WTO International Trade Center: Overview of Organic Wildlife Collected Products. Geneva: ITC, 91 p. (2007). 
[7] C.C.Leao Tarciso \& Lobo, Diele \& Scotson, Lorraine. (2017). Wildlife Management and Sustainability. Ecological Economics. 140. 14-21. 10.1016 / j.ecolecon.2017.04.030.

[8] Shankar, Sriram and Quiggin, John: Production under uncertainty: a simulation study. Journal of Productivity Analysis, 39, 207-215 (2013).

[9] K. Zimmermann. Interval linear systems and optimization problems over max-algebras. In Linear Optimization Problems with Inexact Data, pp. 165-193. Springer, (New York, 2006).

[10] E. K. Boltvina, Ya.M. Ivanyo. Optimization models for harvesting wild-growing products with interval parameters [Modeli optimizatsii zagotovki dikorastushchey produktsii s interval'nymi parametrami] // Vestnik ISTU. 2016. N 6, pp. 73-81.

[11] S.M. Muzyka. Mushrooms of the North Sayan region (composition, ecological features and resources) [Griby severnogo Prisayan'ya (sostav, ekologicheskiye osobennosti i resursy)] (IrSAA, Irkutsk:, 2002), 154 p.

[12] Report on research work on the topic: "Zoning potential reserves of wild-growing resources of the Irkutsk region on harvesting priorities" [Zonirovaniye potentsial'nykh zapasov dikorastushchikh resursov Irkutskoy oblasti po prioritetam zagotovki] / Ya.M. Ivanyo, B.N. Ditsevich, A.A. Luzan, S.M. Music, SA Petrova, Yu.V. Stolopov. (Irkutsk SAU, Irkutsk:, 2018), 163 p.

[13] Yu.E. Vashukevich N.A. Kruzhkov. The history of the Irkutsk trust of the cooperative [Istoriya Irkutskogo tresta koopzveropromkhozov]. (Irkutsk SAU Publishing House, Irkutsk, 2013), 147 p.

[14] L. B. Sopin, L B. Novak, D.F. Leontyev, G.V. Chudnovskaya. Guidelines for the study of wild resources [Metodicheskiye ukazaniya po izucheniyu resursov dikorastushchikh]. (ISHI, Irkutsk, 1991), 48 p.

[15] A.I. Chuprov Efficiency of labor in the collection of wild berries [Effektivnost' truda na sbore dikorastushchikh yagod] / Forestry, 1982. N 9, pp. 20-23.

[16] Mathematics: Encyclopedia [Matematika: Entsiklopediya] / Ed. Yu.V. Prokhorov (Great Russian Encyclopedia M., 2003), 845 p.

[17] Ya.M. Ivanyo, A.A. Luzan, S.A. Petrova , M.N. Polkovskaya. Probabilistic models for estimating harvesting of wild-growing products in the Irkutsk region [Veroyatnostnyye modeli otsenki zagotovki dikorastushchey produktsii v Irkutskoy oblasti] / Actual issues of agrarian science, (Irkutsk SAU Publishing House, Irkutsk, 2017), N 25, pp. 62-68.

[18] N.N. Makagonova Encyclopedia of knowledge based on ontologies [Entsiklopediya znaniy, osnovannaya na ontologiyakh] / Information and mathematical technologies in science and management. Proceedings of the XIX Baikal All-Russian Conference. (Energy Systems Institute Publishing House, Irkutsk, 2014), pp. 153-158.

[19] L.V. Massel Convergence of studies of critical infrastructures, quality of life and safety [Konvergentsiya issledovaniy kriticheskikh infrastruktur, kachestva zhizni i bezopasnosti] / Collection of Information Technologies and Systems. - Works of the sixth international scientific conference (Chelyabinsk State University Publishing House, Chelyabinsk 2017), pp. 170-175.

[20] Decision Support Systems, ACM Transactions on Information Systems (9: 1), (January 1991), pp. 75-95. 